\title{
Notes from the Packaging Laboratory: Hot Tack Measurements of Thin Sealant Films ${ }^{1}$
}

Kenneth R. Berger, Matthew Knoelke, Bruce Welt ${ }^{2}$

\section{Abstract}

Sample preparation can greatly influence the results of laboratory testing of packaging sealant strength. Factors such as test strip width, edge uniformity, sealing die temperature and die load are recognizable variables to control.

A design of experiments approach was used to explore the rank importance of these factors and any interactive effects that may occur. A generally well-behaved ethylene vinyl acetate (EVA) sealant on a high density polyethylene (HDPE) film was used for these tests. Experimental results indicate that sample width, die temperature and die pressure are the most influential factors. Unexpectedly, edge effects, namely a regular sine wave pattern and a generally random irregular edge had little influence on hot tack results.

\section{Background}

The strength of freshly made package seals, hot tack, has been of interest since the development of automated packaging machines. Methods have been developed to measure such properties of packaging materials on packaging machines and in the laboratory. Mobil Films Research used beans dropped on hot seals of a full scale vertical form fill seal machine. DuPont developed a series of bone-shaped spring sheet steel to test hot tack in the lab with a variety of lab die sealers. Frito-Lay attached a weighted stirrup to a looped strip of packaging that threaded through a frame apparatus attached to a lab sealer. (1-6)

The quality of heat-sealed packages is based on factors of time, temperature, pressure or load and sealing die alignment. A review of the several means of creating a heat seal of thin films can be found in Wiley's Encyclopedia of Packaging Technology.

These early methods required many separate tests to determine the hot tack of a film at a specific temperature. The tests were laborious and time consuming. Automated lab hot tack test devices provide an ease of use not present in the early methods. Graphs of hot tack as the sealant cools are readily available. Despite these advantages in actual use, sample preparation and handling may cause data to be distorted or may decrease the accuracy and reproducibility of the data. Also, concerns do arise as

1. This document is ABE340, one of a series of the Agricultural and Biological Engineering Department, Florida Cooperative Extension Service, Institute of Food and Agricultural Sciences, University of Florida. First published December 2002. Please visit the EDIS Web site at http://edis.ifas.ufl.edu.

2. Kenneth R. Berger, assistant professor; Matthew Knoelke, graduate student; and Bruce Welt, assistant professor; Agricultural and Biological Engineering Department, Institute of Food and Agricultural Sciences, University of Florida, Gainesville. 
to whether these devices reveal variance in the materials tested or variance in the test devices.

\section{Objective}

The objective of this experiment was to test the influence of sample preparation and operating settings on hot tack testing of packaging films. The tested parameters were selected with interest in establishing sample preparation and operating standards that can be used to produce consistent reproducible results regardless of the machine, machine operator, or laboratory in which films are hot tack tested. This experiment was designed to test the effects of four specific preparation and operating procedures on hot tack peel strength:

- Sealing die temperature.

- Sealing die pressure settings.

- Sample edge form or type

- Sample width.

\section{Materials and Equipment}

An automated precision lab sealer with an integral tensile tester made by Theller Engineering of Petaluma, California, was used for this experiment. The sealant film (Film B) is a coextruded film from Printpack of Atlanta, Georgia, with a HDPE carrier film and an EVA sealant. Test specimens of the film were prepared with a Fiskars rotary cutter using a flat circular cutting wheel, a repeated pattern wave edge wheel, a perforated edge wheel and a semi-random deckle wheel. Below is an image (Figure 1) of the sine wave and deckle (random) wheels with a reference ruler to illustrate the edge pattern obtained from these cutting wheels.

The wave wheel had a period of about $1.7 \mathrm{~cm}$ and an amplitude of about $0.15 \mathrm{~cm}$. The deckle or random pattern repeated about every revolution of the wheel, about every $14 \mathrm{~cm}$, and had no amplitude greater than $0.10 \mathrm{~cm}$. The perforated wheel had cutting edges 2 $\mathrm{mm}$ long and a gap of $1 \mathrm{~mm}$ long between each cutting edge.

The rotary cutter allowed preparation of multiple samples of test strips with different edge patterns.

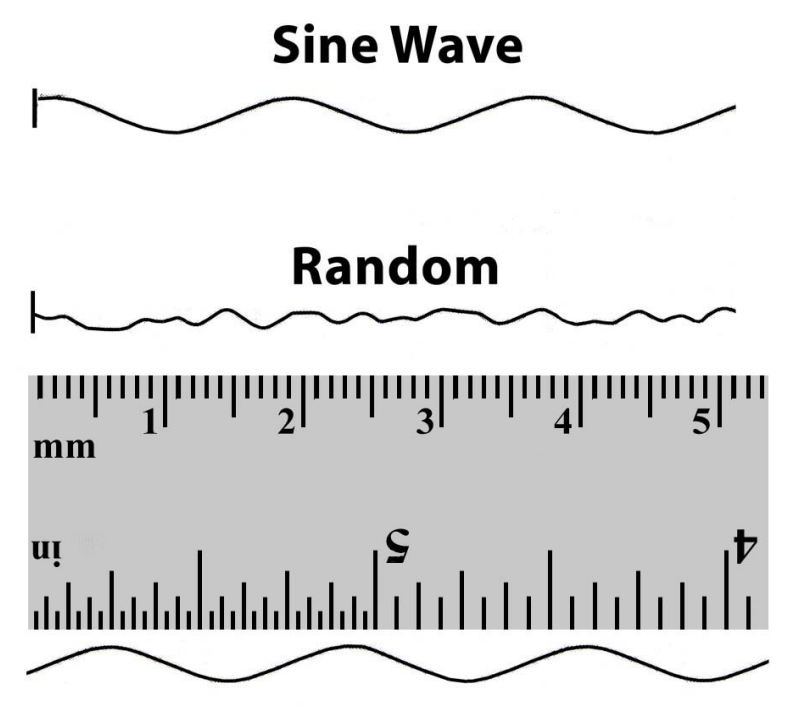

Figure 1. Illustrrations of two difference edge cuts: sine wave and random. A section of a ruler is shown for scale.

Also by marking the square sheet of film to be prepared, a steel ruler was used to consistently establish the width of each specimen cut regardless of the edge effect cutting wheel used. Basically, a film sheet was placed on the cutter, marked with a reference point easily read against the ruler, then the first edge cut. The reference point was moved over the desired distance for the width of the sample and the second edge cut.

\section{Method}

A series of preliminary hot tack tests were performed with the film B using the standard one-inch width and straight edge to confirm that the film provides consistent repeatable results. The standard machine settings for actuation of events were used. The preliminary tests were also used to establish useful temperature and pressure ranges for experimentation. Since the standard sample width for the Theller heat sealer was one inch, the clamps that hold the sample in the machine, are designed for a maximum sample width of one inch. In order to use a wider sample, it was necessary to trim the ends of the sample strip to a one-inch width. A series of tests with wider-than-standard samples were performed to ensure consistent repeatable results. The tested range of sample widths was $0.75 \mathrm{inch}, 1 \mathrm{inch}$, and 1.25 inch. 
Preliminary hot tack testing was done to establish useful temperature and pressure ranges for the Printpack film. The film appeared to yield the best results in the range of 80 to 90 Centigrade. Anything much below 80 or above 90 yielded reduced seal strength. The pressure range that was selected was $689 \mathrm{KPa}$ to $2,068 \mathrm{KPa}$ (100 to $300 \mathrm{psi}$ avg). The pressure reading used is the average reading given by the machine using the default area setting of 0.500 square inch. Samples were cut parallel to the machine direction of the film and their hot tack results were compared to samples cut perpendicular to machine direction tested under otherwise identical conditions. The results of the parallel-cut films were more consistent, so parallel to machine direction was established as the standard method of cutting the Printpack film for this experiment.

Before any samples were cut, a sufficient number of slabs of film were cut parallel to the machine direction. The sample slabs were then randomized so that any possible effects caused by irregularities in the film from one end of the roll to the other would be averaged throughout the results.

All samples were cut using a Fiskars rotary blade cutter. Four different blades were used to produce the four edge types: straight, perforated, wave and deckle (random). The straight blade produces a clean straight edge. The perforated blade produces a perforated edge that must then be torn loose from the rest of the material. The wave blade produces a consistent sinusoidal wave edge (the edges of each sample were cut in-phase to produce consistent sample width). The deckle blade produces an irregular edge. The cutting wheels are approximately $45 \mathrm{~mm}$ in diameter. For a description of test variables and ranges used in the experimental design, see Table 1.

Software from ECHIP, Inc., was used to create the experiment design. The temperature, width, and pressure were entered as continuous (numerical) variables. The edge was entered as a categorical variable. For continuous variables, ECHIP accepts the upper and lower numerical limits and uses them to create the experiment design. Categorical variables are used when no numbers are associated with the variable, and it is necessary to enter more than an upper and lower limit. A linear experiment design was used because it allowed a combination of the two variable types. The ECHIP experiment design software used the information that was entered to create a series of 21 trials in which the ECHIP software specified which combination of variables to use for each trial. One trial was also run that represents a midpoint. The midpoint test was a 2.54 $\mathrm{cm}$ ( 1 in.) wide sample cut with a straight edge wheel, tested at 85 degrees C. and $1379 \mathrm{KPa}(200$ psi). Table 2 summarizes the experimental trials.

The program that controls the heat sealer produces a force vs. time graph and then performs a regression and extrapolation back to zero. It then lists the force in Newtons for $0 \mathrm{~ms}, 125 \mathrm{~ms}$, and $250 \mathrm{~ms}$. Each of the 21 trials was run six times consecutively and then the HT program's average function was used to calculate the average of the data in each column. The average value was then entered into its respective place in the result section of ECHIP for data analysis. Data were analyzed using ECHIP. For each source, the software produced a "summary of results using zero to three stars next to each variable to indicate the effect of that variable on the data. The summary indicated that the edge shape had no effect. The summary also did not indicate a LOF (lack of fit).

Table 3 summarizes the experimental results for each by showing the peel force in newtons at various times. Table 4 shows a ranking of the experimental design factors.

\section{Conclusions}

Sample width, die temperature and die pressure or load, in that order, are the key factors influencing the data, an expected outcome. The edge patterns on the test specimens would also be expected to have a significant influence on the data. However, even with the lack of edge uniformity in some of the strip samples, these factors unexpectedly play little or no part in the hot tack data obtained. It may be that the range of seal strengths $(0.88 \mathrm{~N}$ to $2.7 \mathrm{~N})$ are relatively high and caused the edge effects to be hidden, although this does not seem likely. 


\section{References}

1. First author was responsible for the packaging laboratory test methods used internally by Frito-Lay from late 1980 to early 1991 . This included creating heat seal, hot tack, film shrinkage, residual solvents and many other test procedures for flexible packaging. These functions included working with instrument suppliers and packaging materials suppliers to have meaningful and functional test procedures.

2. Standard Test Method for Hot Tack of Wax-Polymer Blends by the Flat Spring Test, American Society of Testing and Materials (ASTM), D 3706 - 88 (Reapproved 1993).

3. Standard Test Method for Seal Strength of Flexible Barrier Materials, American Society of Testing and Materials (ASTM), F $88-00$.

4. The Wiley Encyclopedia of Packaging Technology, 2nd Edition, 1997, Sealing, Heat, page $823-827$.

5. Hot Tack Testing: A Review, Alister M. Soutar, Journal of Plastic Film and Sheeting, Vol 12, October 1996, p304.

6. Hot Tack Testing: A Review, Penti Sinko and Sauli Tormala, Journal of Plastic Film and Sheeting, Vol 12, October 1996, p335. 
Notes from the Packaging Laboratory: Hot Tack Measurements of Thin Sealant Films

Table 1. Description of Test Variables and Ranges used in Experimental Design.

\begin{tabular}{||l|l||}
\hline \hline Variable & Range Tested \\
\hline Sample Width & 1.91 to $3.18 \mathrm{~cm}(0.75$ to $1.25 \mathrm{inch})$ \\
\hline Die Temperature & 70 to 80 Centigrade \\
\hline Die Pressure & 689 to $2068 \mathrm{KPa}(100$ to $300 \mathrm{PSI})$ \\
\hline $\begin{array}{l}\text { Sample Edge } \\
\text { Type }\end{array}$ & $\begin{array}{l}\text { Straight } \\
\text { Wave } \\
\end{array}$ \\
& Deckle (Random) \\
& Perforated \\
\hline \hline
\end{tabular}

Table 2. Experimental Trials for Designed Experiment: Specimen Types.

\begin{tabular}{|c|c|c|c|c|}
\hline Trial \# & $\begin{array}{l}\text { Sample Width } \\
\mathrm{cm} \text { (in.) }\end{array}$ & Temp.C. & Pressure KPa (psi) & Edge Type \\
\hline 20 & $1.91(0.75)$ & 90.0 & $689(100)$ & Perforated \\
\hline 3 & $3.18(1.25)$ & 80.0 & $2068(300)$ & Straight \\
\hline 1 & $1.91(0.75)$ & 80.0 & $689(100)$ & Straight \\
\hline 6 & $2.54(1.25)$ & 80.0 & $2068(300)$ & Wave \\
\hline 8 & $1.91(0.75)$ & 80.0 & $689(100)$ & Perforated \\
\hline 3 & $3.18(1.25)$ & 80.0 & $2068(300)$ & Straight \\
\hline 12 & $3.18(1.25)$ & 90.0 & $689(100)$ & Deckle \\
\hline 4 & $1.91(0.75)$ & 80.0 & $689(100)$ & Deckle \\
\hline 9 & $3.18(1.25)$ & 90.0 & $689(100)$ & Wave \\
\hline 19 & $3.18(1.25)$ & 90.0 & $2068(300)$ & Straight \\
\hline 11 & $1.91(0.75)$ & 90.0 & $2068(300)$ & Wave \\
\hline 5 & $3.18(1.25)$ & 90.0 & $689(100)$ & Perforated \\
\hline 18 & $3.18(1.25)$ & 90.0 & $2068(300)$ & Perforated \\
\hline 17 & $3.18(1.25)$ & 90.0 & $2068(300)$ & Deckle \\
\hline 15 & $1.91(0.75)$ & 90.0 & $2068(300)$ & Perforated \\
\hline 14 & $3.18(1.25)$ & 80.0 & $2068(300)$ & Deckle \\
\hline 4 & $1.91(0.75)$ & 80.0 & $689(100)$ & Deckle \\
\hline 5 & $3.18(1.25)$ & 90.0 & $689(100)$ & Perforated \\
\hline 2 & $3.18(1.25)$ & 90.0 & $689(100)$ & Straight \\
\hline 16 & $1.91(0.75)$ & 80.0 & $689(100)$ & wave \\
\hline 21 & $3.18(1.25)$ & 90.0 & $2068(300)$ & Wave \\
\hline 1 & $1.91(0.75)$ & 80.0 & $689(100)$ & Straight \\
\hline 10 & $3.18(1.25)$ & 80.0 & $2068(300)$ & Perforated \\
\hline 2 & $3.18(1.25)$ & 90.0 & $689(100)$ & Straight \\
\hline 7 & $1.91(0.75)$ & 90.0 & $2068(300)$ & Deckle \\
\hline 13 & $1.91(0.75)$ & 90.0 & $2068(300)$ & Straight \\
\hline Mid & $2.54(1.00)$ & 85.0 & $1379(200)$ & Straight \\
\hline
\end{tabular}


Table 3. Experimental Data Results - Peel Force in Newtons at Extrapolated 0 milliseconds (ms) , $125 \mathrm{~ms}$ and $250 \mathrm{~ms}$ of Cooling Time, Average of 6 Machine Runs Per Sample Type.

\begin{tabular}{|c|c|c|c|}
\hline Trial & $0 \mathrm{~ms}$ & $125 \mathrm{~ms}$ & $250 \mathrm{~ms}$ \\
\hline 20 & 1.25 & 1.75 & 2.24 \\
\hline 3 & 1.6 & 2.52 & 3.43 \\
\hline 1 & 1.1 & 1.7 & 2.3 \\
\hline 6 & 1.85 & 2.69 & 3.54 \\
\hline 8 & 0.99 & 1.62 & 2.24 \\
\hline 3 & 1.82 & 2.74 & 3.66 \\
\hline 12 & 2.18 & 2.89 & 3.6 \\
\hline 4 & 0.94 & 1.59 & 2.24 \\
\hline 9 & 1.63 & 2.5 & 3.37 \\
\hline 19 & 2.35 & 3.11 & 3.87 \\
\hline 11 & 1.37 & 1.93 & 2.49 \\
\hline 5 & 2.03 & 2.81 & 3.58 \\
\hline 18 & 2.4 & 3.12 & 3.84 \\
\hline 17 & 2.38 & 3.04 & 3.69 \\
\hline 15 & 1.34 & 1.96 & 2.59 \\
\hline 14 & 1.76 & 2.7 & 3.64 \\
\hline 4 & 1.08 & 1.7 & 2.32 \\
\hline 5 & 2.3 & 2.9 & 3.51 \\
\hline 2 & 2.21 & 2.86 & 3.51 \\
\hline 16 & 1.13 & 1.66 & 2.19 \\
\hline 21 & 2.62 & 3.19 & 3.75 \\
\hline 1 & 0.88 & 1.48 & 2.07 \\
\hline 10 & 1.73 & 2.61 & 3.49 \\
\hline 2 & 2.16 & 2.85 & 3.55 \\
\hline 7 & 1.33 & 1.95 & 2.58 \\
\hline 13 & 1.41 & 2 & 2.59 \\
\hline
\end{tabular}

Table 4. Summary Results by Sources: Rank Importance of Factors Used in the Experimental Design.

\begin{tabular}{|c|c|c|c|c|}
\hline \multicolumn{4}{|c|}{ Seal Strength at Time After Sealing Jaws Open } & \multirow[t]{2}{*}{ Factors } \\
\hline Oms & $125 \mathrm{~ms}$ & $250 \mathrm{~ms}$ & & \\
\hline$* * *$ & $* \star *$ & $* \star *$ & 1 & Width \\
\hline ** & ** & ** & 1 & Temp. Celsius \\
\hline--- & 0 & *** & 1 & Pressure \\
\hline--- & --- & --- & 3 & Edge \\
\hline--- & --- & --- & 3 & (Width)(Edge) \\
\hline- & -- & - & 3 & (Temp. Celsius)(Edge) \\
\hline--- & --- & --- & 3 & (Pressure)(Edge) \\
\hline
\end{tabular}

